\title{
Spatial Variations in the Diurnal Pattern of Precipitation over Nepal Himalayas
}

\author{
Dibas Shrestha ${ }^{1}$ and Rashila Deshar ${ }^{2}$ \\ ${ }^{I}$ Nepal Academy of Science and Technology, Lalitpur, Nepal \\ ${ }^{2}$ Central Department of Environmental Science, Tribhuvan University, Kathmandu, Nepal \\ e-mail:st.dibas@yahoo.com
}

\begin{abstract}
The Central Himalayan Region (Nepal Himalayas), comprised of two clear sub-parallel mountain ranges, is a typical location for studying the impact of rugged topography on spatiotemporal variations of precipitation. The relationship between topography and diurnal cycles of rainfall have been investigated utilizing 13-year (19982010) high resolution $\left(0.05^{\circ} \times 0.05^{\circ}\right)$ Tropical Rainfall Measuring Mission (TRMM) Precipitation Radar (PR) data. An investigation of diurnal cycle of precipitation revealed an afternoon maximum during the pre-monsoon season (March-May) and midnight-early morning maximum during the summer monsoon season (June-August) over the southern slopes of the Himalayas. The summer monsoon exhibited a robust spatial variation of diurnal cycle of precipitation, during afternoon-evening time, primary rainfall peak appeared along the Lesser Himalayas ( 2,000-2,200 m above mean sea level), while early-morning rain in contrast showed maximum concentration along the southern margin of the Himalayas ( $\sim 500-700 \mathrm{~m}$ above MSL). An afternoon-evening rainfall peak was attributed to higher rain frequency, whereas early-morning rainfall peak was attributed to fewer but rather intense rainfall. It is suggested that, confluence between down slope and moist southeasterly monsoon flow triggers convection near the foothills of the Himalayas during early morning period. The results further suggested the morning precipitation moves southward in the mature monsoon season.
\end{abstract}

Key words: rainfall, diurnal cycle, orographic forcing, TRMM, precipitation radar

\section{Introduction}

Nepal Himalayas (NH) is the central portion of 2500 $\mathrm{km}$ long Himalayas, which stretches from Afghanistan to Myanmar. This portion is a home of world's highest peaks including Mount Everest. In contrast to the eastern and western Himalayas, Nepal Himalayas is characterized by three sub-parallel ranges: the Greater Himalayas (GH), the Lesser Himalayas (LH) (also known as the Mahabharat Range), and the SubHimalayas ( $\mathrm{SH}$ ) (also known as the Siwalik Range) (Bookhagen \& Burbank 2006, Shrestha et al. 2012). The sub-parallel ranges exert a significant influence on spatial and temporal variation of rainfall (Anders et al. 2006, Bhatt \& Nakamura 2005, Bookhagen \& Burbank 2006, Shrestha et al. 2012). One of the most significant features of precipitation over land is diurnal variation. Several studies have been conducted to study the diurnal variation of rainfall over the Himalayan territory (Nesbitt \& Zisper 2003, Bhatt \& Nakamura 2006, Romatschke \& Houze 2011a, 2011b). A typical feature of the diurnal cycle was observed over the southern slope of the Himalayas during the mature monsoon season. By monitoring precipitation in 2001 summer monsoon in the Himalayas on the basis of basin-wide observations in central Nepal, Barros and Lang (2003) observed nocturnal rainfall maxima over the southern slope of the Himalayan region. This finding was strongly supported by Bhatt and Nakamura's (2005 \& 2006) observation on the basis of TRMM PR near-surface rainfall data. They suggested that a significant increase in moisture, presence of down-valley wind at midnight, and gravity 
waves might produce favorable conditions for nocturnal rainfall. Further, it stated that the earlymorning southward shifting of the precipitation system is due to the existence of a down slope density current. Essentially, daytime precipitation is concentrated over the ridge with strong ridge-valley gradients, and during midnight-early morning, intense rainfall concentrates over ridges and in river valleys (Bhatt \& Nakamura 2005, Higuchi et al. 1982).

Studying diurnal cycle of precipitation in the Nepal Himalayas is particularly challenging due to lack of adequate high temporal resolution data. Direct measurements of precipitation in mountain environments are particularly challenging, because of the need to cover a large range of elevations and orographic positions. In addition, in the mountainous region, it is often difficult to install rain gauges at higher elevations because of steep hillslopes, harsh weather, and lack of roads and transportation. On the other hand, the physiographic features and the complex atmospheric processes significantly modify the distribution of precipitation. Hence, in the mountainous areas where large variability in the precipitation exists, the gauge network is never adequate to define the detailed precipitation distribution. In this context, the Precipitation Radar (PR) onboard the Tropical Rainfall Measuring Mission (TRMM) revolutionized the global view of precipitation distribution and mechanisms by providing high spatial resolution with an ability to profile the vertical structure of precipitation.

We aim to study and characterize the seasonal diurnal cycle of precipitation and its relationship with altitude over the southern slopes of the Nepal Himalayas (Fig. 1) by utilizing hourly $0.05^{\circ} \times 0.05^{\circ}$ grid data from the TRMM PR. Due to the TRMM PR's poor temporal resolution, there are fewer possibilities to study temporal variability in detail from PR measurements especially at small spatial scales $(5 \mathrm{~km})$ (Bhatt \& Nakamura 2005). We therefore, make use of accumulation over 6-h of local time to estimate the horizontal distribution of the diurnal cycle of precipitation. The rain total and conditioned rain rate estimates are used to express spatial variability in precipitation.

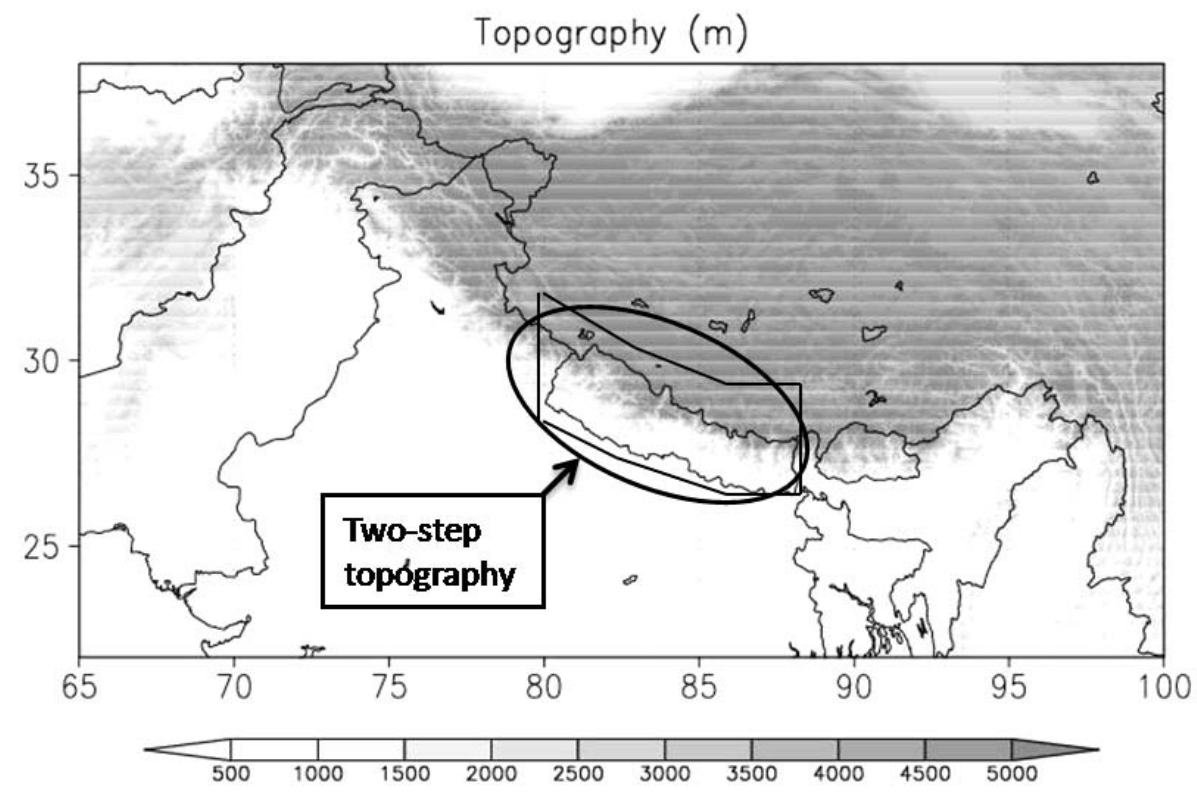

Fig. 1. Topographic overview of the Himalayan range. International boarders are outlined in black. Eastern and western Himalayan regions are characterized by one-step topography; the central Himalayas are characterized by two-step topography. The area bounded by the thin black line represents the study area for statistical analysis.

\section{Methodology}

The data and methods of analysis used in this study are described by Shrestha et al. (2012). As in the study, we used TRMM satellite's PR version 6 products for pre-monsoon (March-May) (MAM) and summer monsoon (June-August) (JJA) for 1998-2010 for use as primary data. Briefly, TRMM PR is the first space 
Dibas Shrestha and Rashila Deshar/Spatial Variations in the Diurnal...........

borne radar designed to provide three-dimensional maps of storm structures (Kumerrow et al. 1998, 2000). PR has horizontal resolution of $\sim 4 \times 6 \mathrm{~km}$ and vertical resolution of $250 \mathrm{~m}$ at nadir with $215-\mathrm{km}$ swath width operating at $13.8 \mathrm{GHz}$. It can detect reflectivities down to nearly $17 \mathrm{dBZ}$, equivalent to rain rates of $\sim 0.5 \mathrm{~mm} / \mathrm{h}$. The pixel size, swath width, and sensitivity to rain changed slightly (5-km pixel size, $247-\mathrm{km}$ swath width and sensitivity reduced by $1.2 \mathrm{~dB}$ ) after an orbit boost from $350 \mathrm{~km}$ to $402.5 \mathrm{~km}$ in 2001 . However, the differences were insignificant and were neglected in this study. To study rainfall patterns, product $2 \mathrm{~A} 25$ (Iguchi et al. 2000) was used; it provided near-surface rain rate from PR. "Near-surface" rain rate was obtained from the range bin closest to the surface that is generally not corrupted by surface clutter. The nearsurface height ranged from $500 \mathrm{~m}$ above ground level (AGL) at nadir to $2000 \mathrm{~m} \mathrm{AGL}$ at the edge of the observation swath. The average rain rate was calculated as a product of rain frequency (number of rain samples normalized by total number of samples) and conditional rain rate (near-surface rain rate only when it was raining).

For data processing, we first binned data from each individual swath onto a regular grid with spacing of $0.05^{\circ}$ (about $5 \times 5 \mathrm{~km}$ ). The gridded data were than averaged over the entire period of record to produce daily-mean climatologies.

For statistical analysis of altitudinal variations, precipitation characteristics were averaged for each $200 \mathrm{~m}$ altitude interval up to 5,000 $\mathrm{m}$ in the Himalayas. The analysis was restricted within 5,000 m elevation because some of the highest altitude pixels showed excessively high magnitudes of rainfall which might be due to ground clutter contamination in radar echoes (Shrestha et al. 2012). Another reason to limit the area to altitudes below $5000 \mathrm{~m}$ elevation is simply to exclude the northern slopes of the Himalayas.

The area-averaged values were smoothed by a $1: 2: 1$ smoothing filter. Smoothed values (SV) are given as

$S V_{a}=\frac{V_{a-1}+2 V_{a}+V_{a+1}}{4}$,

where $V$ and $a$ represent the averaged value and altitude, respectively.
Other than TRMM PR data, the GTOPO30 data set of the United States Geological Survey (USGS) with a spatial resolution of $0.008^{\circ} \times 0.008^{\circ}$ was used for topographic data analysis. For this study, data were averaged over $0.5^{\circ} \times 0.5^{\circ}$ grids.

\section{Results and Discussion Horizontal distribution}

First, we analyzed the horizontal distribution of the diurnal variation of rainfall for two seasons premonsoon (MAM) and monsoon (JJA). Figure 2 shows the six-hourly distribution of rainfall total from earlymorning (0000-6000 LST) to midnight (1800-2400 LST) for the summer monsoon period. It was observed that rain system was more active during late-afternoon to early-morning time (Figs. 2c and 2d). The earlymorning (0000-0600 LST) rain totals appeared more common over the lower elevation areas (Fig. 2a). However, the higher terrain (Lesser Himalayas) also exhibited similar behavior during this time period. The late-morning rain (0600-1200 LST) appeared dominant over the lower elevation areas (Fig. 2b). The large amount of rainfall in contrast were found over the higher terrain region around $2000 \mathrm{~m}$ contour line during afternoon periods (1200--1800 LST), which was more significant during evening-midnight periods (1800-2400 LST). Previously, Bhatt and Nakamura (2005) found similar spatial pattern in the diurnal cycle of rainfall over the southern slopes of the Himalayas during monsoon season. Our results showed that large rain totals appeared below $3000 \mathrm{~m}$ MSL. This was not consistent with the findings of Kurosaki and Kimura (2002), who showed daytime (0900-1500 LST) rainfall maxima and cloudiness above $3000 \mathrm{~m}$ above mean sea level (AMSL) over the south-facing slopes of the eastern Himalayas. According to Kurosaki and Kimura (2002), greater cloud cover frequency $(\sim 75 \%)$ of low clouds was observed above $3000 \mathrm{~m}$ AMSL over the south-facing slopes of the eastern Himalayas during the pre-monsoon and monsoon seasons. Bhatt and Nakamura (2005) explained that the disagreement might be due to the existence of non-precipitating-type clouds along the tallest ridges in the eastern Himalayas. This is because their analysis did not discriminate precipitating clouds from non-precipitating clouds. Despite this, the spatial variability between the reported cloud field and the PR-observed rainfall distribution were in agreement for the south-facing slopes. 

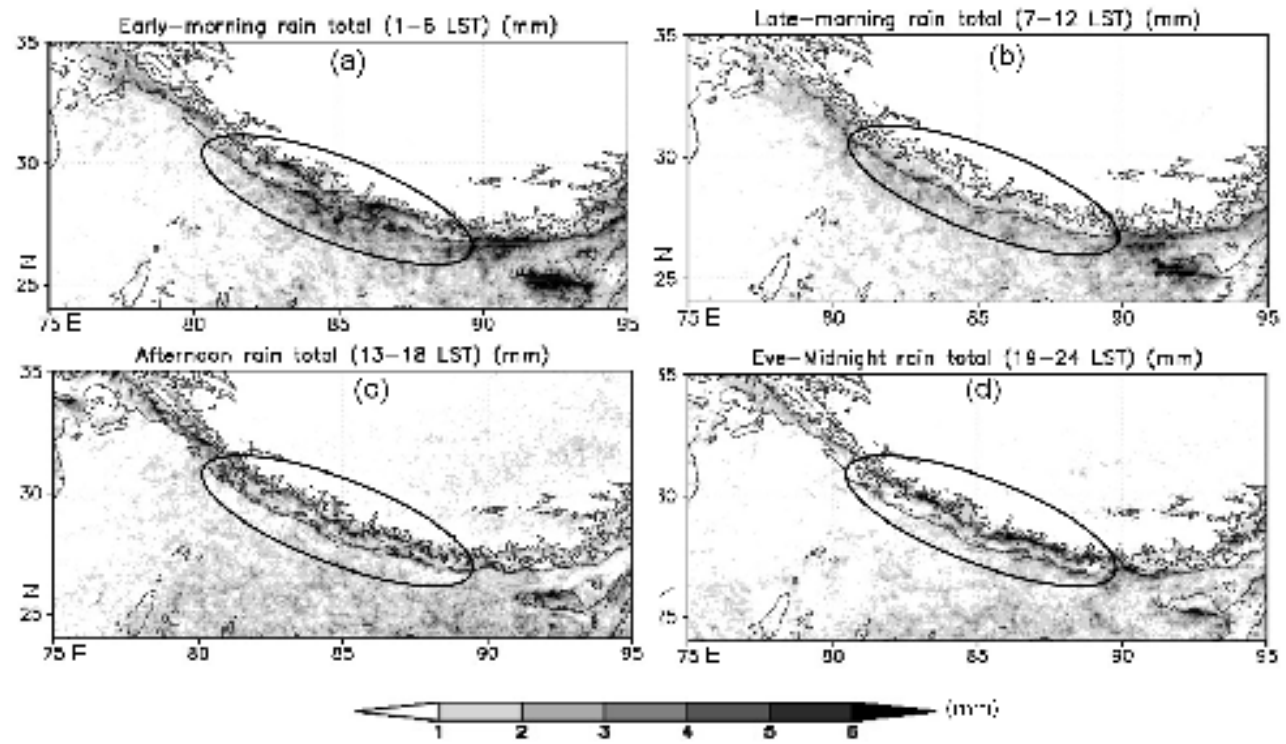

Fig. 2. Mean 6-hourly rainfall amount distribution for JJA of the 13-yr period 1998-2010: (a) Early-morning (0000-0600 LST), (b) Late-morning (0600-1200 LST), (c) Afternoon (1200-1800 LST), and (d) Evening-Midnight (1800-2400 LST). Contour lines indicate 500, 2000, and $4000 \mathrm{~m}$ elevations. Area enclosed by the black oval lines represents the central Himalayan region (CHR).

Further, the horizontal distribution in the diurnal pattern of rain frequency and conditional rain rate was studied in order to identify the factor responsible for high rain total in particular location and time (Figs. 3 and 4). The PR observations showed that strong/weak conditional rain frequency exists mornings/afternoons along the Himalayan foothill region. This inference is consistent with results shown by Bhatt and Nakamura (2005), and
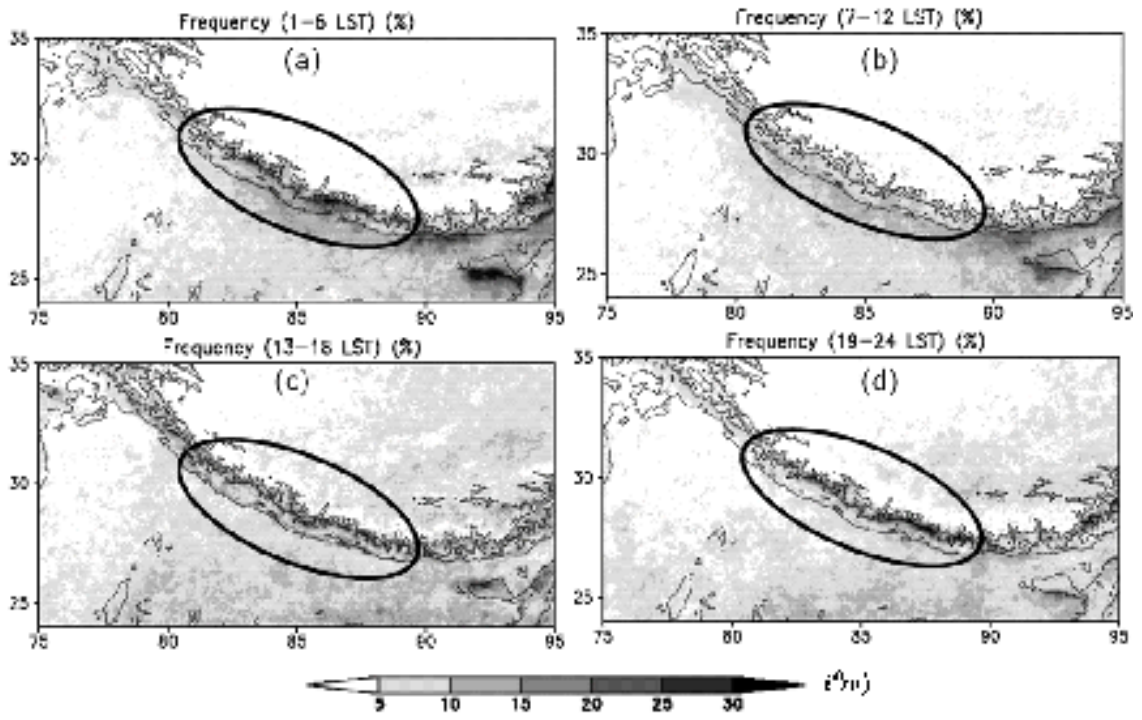

Kurosaki and Kimura (2002). Ohsawa et al. (2001) also noticed convective activity along the eastern Himalayan foothills in the morning during monsoon period. In general, early-morning rainfall over foothill regions and $\mathrm{SH}$ regions is a consequence of strong conditional rain rate whereas afternoon to midnight rainfall maxima over LH regions is a consequences of relatively very high frequency of rainfall.

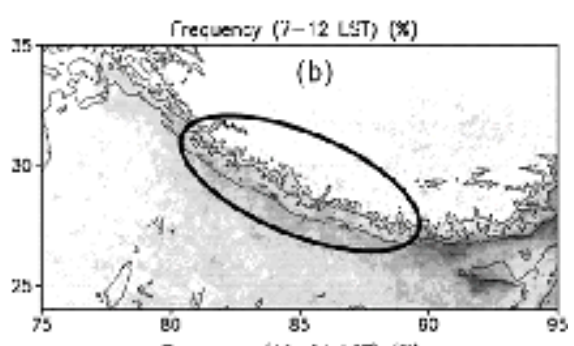

Fig. 3. Mean 6-hourly rain frequency distribution for JJA of the 13-yr period 1998-2010: (a) Early-morning (0000-0600 LST), (b) Late-morning (0600-1200 LST), (c) Afternoon (1200-1800 LST), and (d) Evening-Midnight (1800-2400 LST). 

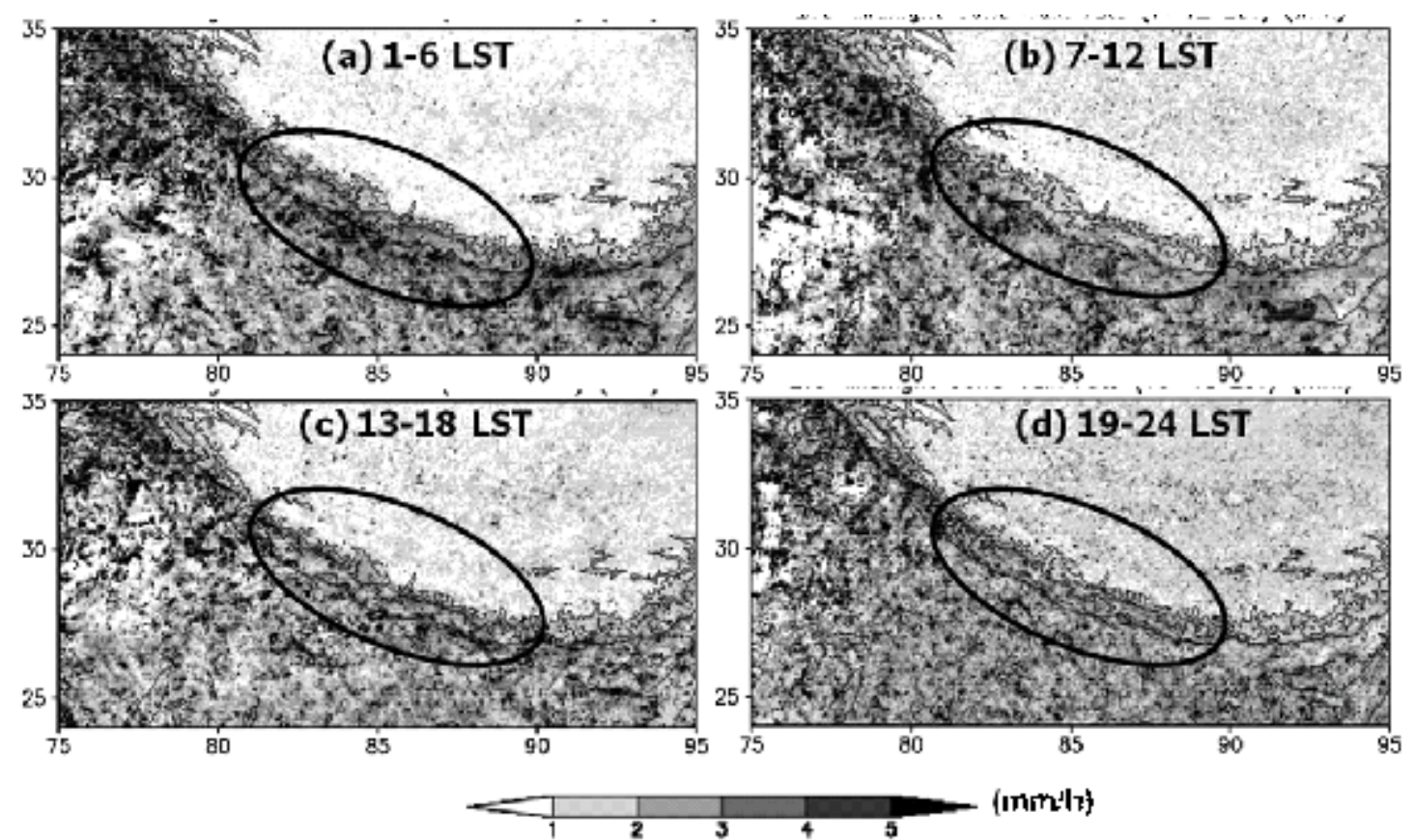

Fig. 4. Mean 6-hourly conditional rain rate for JJA of the 13-yr period 1998-2010: (a) Early-morning (0000-0600 LST), (b) Late-morning (0600-1200 LST), (c) Afternoon (1200-1800 LST), and (d) Evening-Midnight (1800-2400 LST).

\section{Altitudinal variation}

To quantify more precisely the relationship between rainfall characteristics and altitude, area-averaged total rainfall, rain frequency, and conditional rain rate over the southern slopes of the Himalayas up to 5,000 $\mathrm{m}$ elevation within Nepal region was analysed (Fig. 1). Averaged values of all the three components for each $200 \mathrm{~m}$ elevation area are presented in Fig. 5 . The figure shows a distinct altitudinal pattern of rainfall during JJA and MAM. There appears a strong diurnal cycle in JJA (Fig. 5b) compared to MAM (Fig. 5a). During MAM, afternoon and evening rainfall appears dominant, particularly over the higher altitude regions. In contrast, evening to midnight (1800-2400 LST) and early-morning (0000-0600 LST) rainfall was dominant in JJA. An interesting result of this study was distinct altitudinal variation of rainfall during evening-midnight and early morning rainfall over the southern slope of the Himalayas. It was observed that the evening-midnight rainfall typically peaked at a mean elevation of $2,100 \mathrm{~m}$ AMSL with a small secondary peak at about $500 \mathrm{~m}$ AMSL. In contrast, early-morning rainfall primarily concentrated at the foothills of the Himalayas ( 500 m AMSL). However, there appeared broad secondary rainfall maxima over the higher altitude areas. During late morning (06001200), rainfall peaked at mean elevation $500 \mathrm{~m}$ MSL, then monotonically decreases with elevation. The afternoon rainfall exhibited altitudinal pattern similar to the evening-midnight rain. The figure showed that the conditional rain rate decreased as elevation increased throughout the day during MAM and JJA. In contrast to conditional rain rate, rain frequency depicted strong diurnal cycle in terms of its altitudinal variations which was similar to the variation of rain total during both seasons. Over all, these results demonstrated that the high-altitude rainfall peak is followed by more frequent nocturnal rainfall rather than a high conditional rain rate. Despite similar rain frequency over low- and high-altitude regions in the early-morning time, a low-altitude rainfall peak was noticed, which indicated that intense early-morning rainfall contributed to a large amount of rainfall over lower elevation areas. 

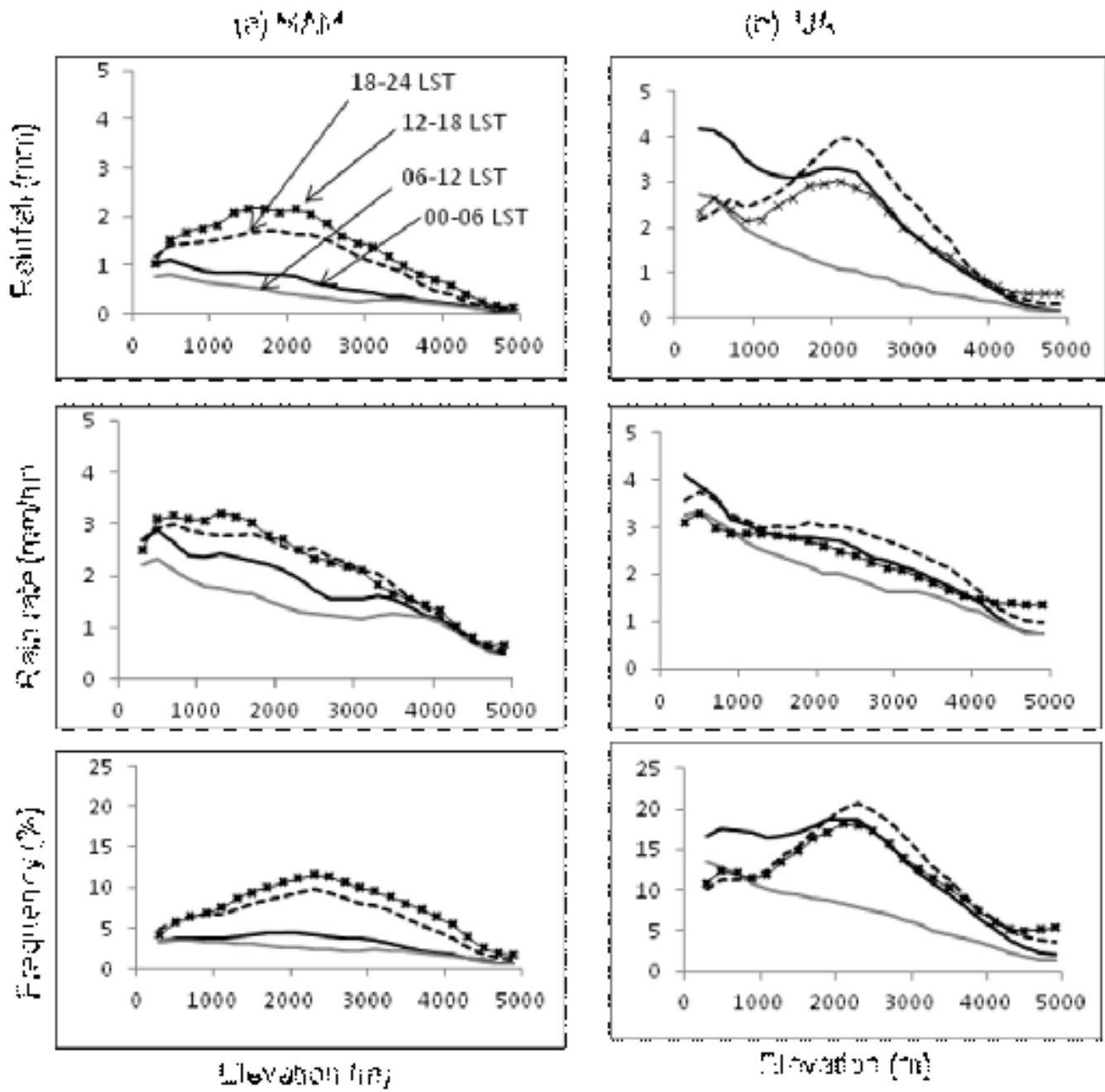

Fig. 5. Diurnal variation of rain characteristics (rain rate, conditional rain rate and rain frequency) with altitude for (a) pre-monsoon (MAM), and (b) monsoon (JJA). Solid black, solid grey, thin solid black (cross mark) and dashed lines represents 0000-0600, 0600-1200, 1200-1800 and 1800-2400 LST, respectively.

\section{Rain-type distribution}

Next, the diurnal cycle of rain-type distribution was analyzed because mountains could generate both stratiform and convective precipitation. Stratiform precipitation generally occurs in a statically stable atmosphere, while convective precipitation results from the release of static instability. Thus, considerable diurnal variation in rain type was also expected over the NH. Information about rain-type distribution and its relationship with altitude could provide valuable insight into mountain rain systems.

Horizontal distribution of rain type depicted that early morning rainfall was more stratiform, which appeared over the broader area of the Lesser Himalayas (Figure not shown). In contrast, afternoon and evening rainfall were mostly convective. The result showed that convective rainfall was more significant during evening rather than afternoon time, which mainly, appeared at high elevation. The altitudinal pattern in diurnal variation of stratiform and convective rain rate and number of events are shown in Fig. 6. The figure showed that the frequency of stratifom rainfall typically peaked at higher elevation (mean elevation $2100 \mathrm{~m}$ MSL) during the evening (Fig. 6d). Similar trend was observed in the afternoon as well with a small secondary peak at a mean elevation $500 \mathrm{~m}$ AMSL 
Dibas Shrestha and Rashila Deshar/Spatial Variations in the Diurnal

(Fig. 6c). Significant stratiform precipitation events were observed at lower elevations in the early morning along with the peak at a high elevation (Fig. 6a). In contrast, the late-morning rainfall depicted monotonically decreasing trends in stratiform rain frequency (Fig. 6b). This suggested that the higher rain total at the higher elevation was a result of afternoonearly morning frequent stratiform rain. There appeared a strong convective rain over $\mathrm{SH}$ in the early morning whereas frequency was higher during afternoon. Convective rainfall activity over higher terrain was less significant. It gives an idea that the mid-night to early-morning rainfall in the $\mathrm{SH}$ regions was generally convective. Clearly, late-afternoon to early morning time rainfall over $\mathrm{SH}$ was stratiform with very high frequency. The diurnal cycle of rainfall we observed in NH was consistent with Barros et al. (2000) and Barros and Lang (2003). The mechanisms that lead to diurnal behavior in $\mathrm{NH}$ were likely the same as noted by Romatschke and Houze 2011 and Bhatt and Nakamura 2006 (i.e, daytime upslope wind and nighttime downslope wind).
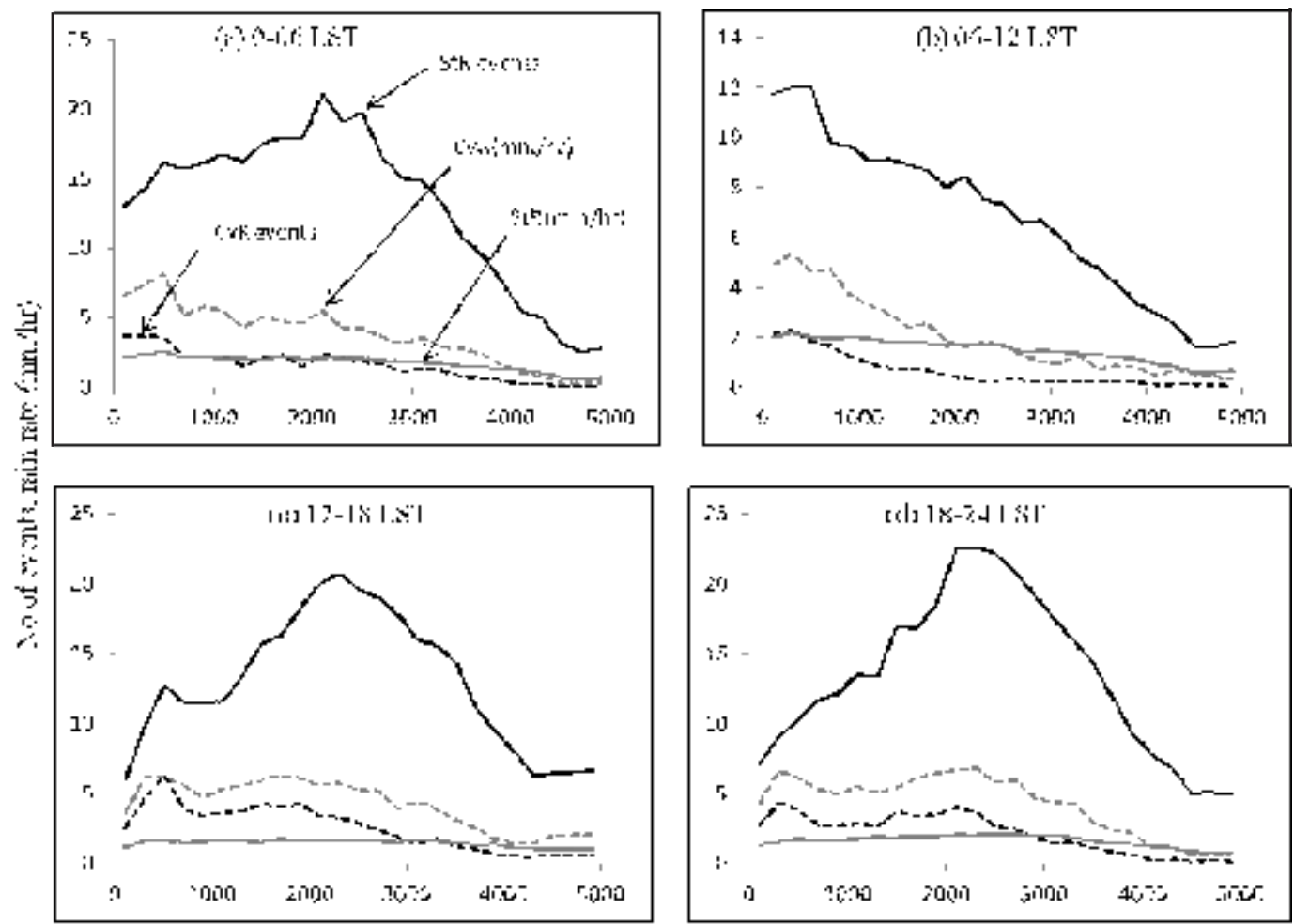

Elwantion i!m!

Fig. 6. Diurnal cycie of rain-type (stratitorm, and convective) with elevation for (a) UUUU-UbUU LS I, (b) UoUU-1 LUU LST, (c) 1200-1800 LST, and (d) 1800-2400 LST. Black solid/dotted lines represents number of stratiform/convective and grey solid/grey lines represents conditional rain rate of stratiform/convective $(\mathrm{mm} / \mathrm{h})$, respectively.

In conclusion, an investigation of diurnal cycle of precipitation revealed an afternoon maximum during the pre-monsoon season and midnight-early morning maximum during the summer monsoon season over the southern slopes of the Himalayas. The summer monsoon exhibited a robust spatial variation of diurnal cycle of precipitation; during afternoon-evening time, primary rainfall peak appeared along the Lesser
Himalayas ( 2,000-2,200 m above MSL), while earlymorning rain in contrast showed maximum concentration along the southern margin of the Himalayas ( 500-700 m above MSL). An afternoonevening rainfall peak was attributed to rain frequency, whereas early-morning rainfall peak was attributed to fewer but rather intense rainfall. It is suggested that, confluence between down slope and moist 
Nepal Journal of Science and Technology Vol. 15, No.2 (2014) 57-64

southeasterly monsoon flow trigger convection near the foothills of the Himalayas during early morning period. The result further suggested the morning precipitation moves southward in the mature monsoon season.

\section{Acknowledgements}

We are thankful to Prof. Kenji Nakamura and Lab of Satellite Meteorology, Hydrospheric Atmospheric Research Center, Nagoya University, Japan for providing TRMM satellite datasets.

\section{References}

Anders, A. H., G. H. Roe, B. Hallet, D. R. Montgomery, N. J. Finnegan and J. Putkonen. 2006. Spatial patterns of precipitation and topography in the Himalaya. Spec. Pap. Geol. Soc. Am. 398: 39-53.

Barros, A. P., M. Joshi, J. Putkonen and D. W. Burbank. 2000. A study of the 1999 monsoon rainfall in a mountainous region in the central Nepal using TRMM products and rain gauge observations. J. Geophys. Lett. 27: 3683-3686.

Barros, A. P. and T. J. Lang. 2003. Monitoring the monsoon in the Himalayas: observations in Central Nepal, June 2001. Mon. Weather Rev. 131: 1408-1427.

Bhatt, B. C. and K. Nakamura. 2005. Characteristics of monsoon rainfall around the Himalayas revealed by TRMM precipitation radar. Mon. Weather Rev. 133: 149-165.

Bhatt, B. C. and K. Nakamura. 2006. A climatologicaldynamical analysis associated with precipitation around the southern part of the Himalayas. J. Geophys. Res. 111: D02, doi:10.1029/2005JD006197.

Bookhagen, B. and D. W. Burbank. 2006. Topography, relief, and TRMM-derived rainfall variations along the Himalaya. Geophys. Res. Lett. 33: L08405, doi:10.1029/2006GL026037.
Higuchi, K., Y. Ageta, T. Yasunari and J. Inoue. 1982. Characteristics of precipitation during the monsoon season in high-mountain areas of the Nepal Himalaya. Hydrol. Sci. J. 27: 251.

Iguchi, T., T. Kozu, R. Meneghini, J. Awaka and K. Okamoto. 2000. Rain-profiling algorithm for the TRMM precipitation radar. J. Appl. Meteor. 39: 20382052.

Kummerow, C., W. Barnes, T. Kozu, J. Shiue and J. Simpson. 1998. The Tropical Rainfall Measuring Mission (TRMM) sensor package. J. Atmos. Oceanic Technol. 15: 809-817, doi:10.1175/1520-0426.

Kummerow, C. et al. 2000. The status of Tropical Rainfall Measuring Mission (TRMM) after two years in orbit. J. Appl. Meteorol. 39: 1965-1982, doi:10.1175/15200450.

Kurosaki, Y. and F. Kimura. 2002. Relationship between topography and day time cloud activity around Tibetan Plateau. J. Meteor. Soc. Japan, 80: 339-355.

Nesbitt, S. W. and E. J. Zisper. 2003. The diurnal cycle of rainfall and convective intensity according to three years of TRMM measurements. J. Clim. 16: $1456-1475$.

Romatschke, U. and R. A. Houze. 2011a. Characteristics of precipitating convective systems in the South Asian monsoon. J. Hydrometeorol. 12: 157-180, doi:10.1175/2010JHM1311.1.

Romatschke, U. and R. A. Houze. 2011b. Characteristics of precipitating convective systems in the premonsoon season of South Asia, J. Hydrometeorol. 12: 3-26, doi:10.1175/2010JHM1289.1.

Shrestha, D., P. Shing and K. Nakamura. 2012. Spatiotemporal variation of rainfall over the central Himalayan region revealed by TRMM Precipitation Radar. J. Geophys Res. 117: D22106, doi: 10.1029/ 2012JD018140.

Ohsawa, T., H. Ueda, T. Hayashi, A. Watanabe and J. Matsumoto. 2001. Diurnal variations of convective activity and rainfall in tropical Asia. J. Meteor. Soc. Japan 79: 333-352. 